\title{
Nanotechnology and Its Application
}

\section{Anupam Rajak *}

Department of Botany, Visva-Bharati University, West Bengal, India

\section{Abstract}

In modern days, technology is growing rapidly. Technology is the benefit of science by promoting the benefit of society. Science is critical to future development of nanotechnology. Nanotechnology is the developments for future. Nanoparticles can cause chronic health effects. Viruses and DNA are examples of natural objects on the nanoscale. Nanoscience is study of manipulation of materials at atomic, molecular and macromolecular scales. Nanotechnology also has the potential opportunities to improves create new and better product. Application of nanomaterials to detect, prevent and remove pollution. Nanotechnologies are design, production and applications of medicine, diagnostic, therapy, sequencing. Nanotechnology may be able to advance environmental protection. Nanotechnology is potential to contribute to reduction in energy. Nanotechnology represents an entire scientific and engineering field. This is rapidly growing and large future market.
\end{abstract}

Keywords: Nanotechnology; Prevent; Nanoparticles; Technology; Future

\section{Introduction}

The term "nanotechnology" was invented at the University of Tokyo in 1971 by Professor Norio Taniguchi. A nanometer is one billionth of meter - about one hundred thousand times smaller than the diameter of a human hair. In our everyday life, nanotechnology manufactures the innovative products to produce the new high performance battery storage systems and lightweight components [1-5]. Not only nanotechnologists, here all fields that is biologist, chemists, doctors and engineers contribute their experience and knowledge to develop our society. Nanotechnology has the potential to the development all sector, ranging from disease diagnosis and treatment to environmental remediation. Nanotechnology is the creation of devices through the manipulation of matter.

Congratulations! You face many challenges every day. Nanotechnology promise to revolutionize drug delivery and medical diagnosis. Nanotechnology stands to produce scientific and technological advances in diverse fields including medicine and physiology. Nanotechnologists are also increasingly playing a role in producing the chips. Nanotechnologies provide the government with an opportunity to make develop a precautionary regulatory framework for a new generation of chemicals and substances. Nanotechnology (nano-small) is the study of small structure. Today, we are facing a major health problem like diabetes, cancer, Parkinson's disease, etc. Nanotechnology repair damaged tissue [6].

\section{Nanotechnology, energy and environment}

Nanotechnology will play role by protecting the environment. Energy is the ability to do work. Energy may be transformed from one into another. Nanotechnologies can storage of energy $[7,8]$.

Nanotechnology can help in developing green technologies that can minimize environmental pollution.

\section{Nanotechnology in dental care}

Millions of people currently poor dental care. Nanorobotics will ensure better oral health. Tooth repair may also involve in nanodental techniques. Uses of nanotechnology to repair lost tooth.

\section{Conclusion}

So, nanotechnology follows biology and information technology. Nanotechnology development in order to quality of life.
Nanotechnology will continue to develop the society and improve the environment in various ways. Today, thanks to nanotechnology, we can buy tennis racket that are stronger. So, future research in this field is necessary for its application.

\section{Acknowledgements}

Thanks to my parents. Finally, thanks to all the friends for their continued support and encouragement.

\section{References}

1. Nikalje AP (2015) Nanotechnology and its Applications in Medicine. Med chem 5: 081-089.

2. Rasheed SAP, Jude M, Suresh K, Dey S, Sunil H, et al. (2016) Nanotechnology and Its Applications in Dentistry. International Journal of Advanced Health Sciences 2: 1-10.

3. Shrivastava S, Dash D (2009) Applying Nanotechnology to Human Health: Revolution in Biomedical Sciences. J Nanotech 1-15.

4. Deb KD, Griffith M, Muinck ED, Rafat M (2012) Nanotechnology in stem cells research: advances and applications.Front Biosci (Landmark Ed) 17: 17471760 .

5. Boisseau P, Loubaton B (2011) Nanomedicine, nanotechnology in medicine. ComptesRendus Physique 12: 620-636.

6. (2010) Nanotechnology in Targeted Cancer Therapy. University of Waterloo

7. LaVan DA, McGuire T, Langer R (2003) Small-scale systems for in vivo drug delivery. Nat Biotechnol 21: 1184-1191.

8. Cavalcanti A, Shirinzadeh B, Freitas RA, Hogg T (2008) Nano robot architecture for medical target identification. Nanotechnology 19: 15.

*Corresponding author: Anupam Rajak, Department of Botany, VisvaBharati University, West Bengal, India, Tel: 3463262751; E-mail: anupamrajak1234@gmail.com

Received: May 28, 2018; Accepted: May 30, 2018; Published: June 04, 2018

Citation: Rajak A (2018) Nanotechnology and Its Application. J Nanomed Nanotechnol 9: 502. doi: 10.4172/2157-7439.1000502

Copyright: (c) 2018 Rajak A. This is an open-access article distributed under the terms of the Creative Commons Attribution License, which permits unrestricted use, distribution, and reproduction in any medium, provided the original author and source are credited. 